\title{
Active and passive procrastination in terms of temperament and character
}

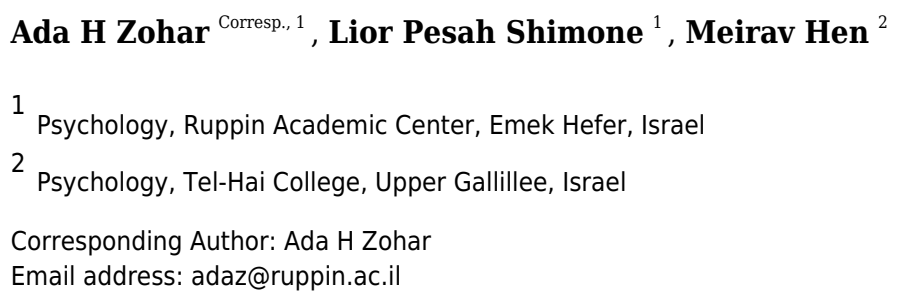

Background: While passive procrastination is usually associated with distress and dysfunction active procrastination may be an effective coping style. To test this possibility, we examined passive and active procrastination in terms of temperament, character, and emotional intelligence (EI), as well as by a short-term longitudinal study. Methods: Adult community volunteers $(\mathrm{N}=126)$ self-reported twice in an online short-term longitudinal study. At baseline on active and passive procrastination, as well as on the temperament and character inventory of personality ( $\mathrm{TCl}-140)$ and El. At first testing, they were asked to freely describe three personal goals and to make action plans to achieve each within the next two weeks. Two weeks later they reported on progress on their personal goals (PPG). Results: PPG correlated positively with active procrastination and negatively with passive procrastination. Dividing the participants into median splits on active and passive procrastination resulted in four groups: Active, Passive, Active-Passive, and NonProcrastinators. Analysis of variance showed that active procrastinators had an advantage in temperament and character traits as well as El. Active procrastinators were also higher than the other groups on personality profiles i.e. combinations of traits; dependable temperament and well-developed character. Conclusions: Active procrastination can be an adaptive and productive coping style. It is associated with dependable temperament, well-developed character, and high emotional intelligence and predicts meeting personal goals. 
G।

Ye

\title{
1 Active and Passive Procrastination in Terms of
}

2 Temperament and Character

3

4

5

6

7

\author{
Ada H. Zohar ${ }^{1}$, Lior Pesah Shimone ${ }^{2}$, Meirav Hen ${ }^{3}$ \\ ${ }^{1}$ Graduate Program In Clinical Psychology, Ruppin Academic Center, Emek Hefer, Israel \\ ${ }^{2}$ Psychology, Tel-Hai College, Upper Galilee, Israel
}

Corresponding Author:

Ada H Zohar ${ }^{1}$

Ruppin Academic Center, Bait 7 office 11, Emek Hefer, Israel 40250

Email address: adaz@ruppin.ac.il

\section{Abstract}

Background: While passive procrastination is usually associated with distress and dysfunction active procrastination may be an effective coping style. To test this possibility, we examined passive and active procrastination in terms of temperament, character, and emotional intelligence (EI), as well as by a short-term longitudinal study. Methods: Adult community volunteers $(\mathrm{N}=126)$ self-reported twice in an online short-term longitudinal study. At baseline on active and passive procrastination, as well as on the temperament and character inventory of personality (TCI-140) and EI. At first testing, they were asked to freely describe three personal goals and to make action plans to achieve each within the next two weeks. Two weeks later they reported on progress on their personal goals (PPG). Results: PPG correlated positively with active procrastination and negatively with passive procrastination. Dividing the participants into median splits on active and passive procrastination resulted in four groups: Active, Passive, Active-Passive, and Non-Procrastinators. Analysis of variance showed that active procrastinators had an advantage in temperament and character traits as well as EI. Active procrastinators were also higher than the other groups on personality profiles i.e. combinations of traits; dependable temperament and well-developed character. Conclusions: Active procrastination can be an adaptive and productive coping style. It is associated with dependable temperament, welldeveloped character, and high emotional intelligence and predicts meeting personal goals.

\section{Introduction}

Procrastination has been extensively studied, especially in college students. It is often considered a self-imposed, self-handicapping behavior, and is associated with a variety of 
38 personality, situational, psychological and motivational variables (Steel , 2007). For example,

39 Ariely and Wertenbroch (2002) in a series of experiments showed that students at MIT did not

40 set themselves meaningful and helpful deadlines in order to overcome procrastination and that

41 their self-imposed deadlines did not contribute to the optimization of their academic performance

42 in a semester-long course, concluding that procrastination was a failure of self-control. Wu, Gui,

43 Lin, Gu, Zhu, and Liu (2016) measured the event related potential of higher and lower

44 procrastinators, finding that high procrastinators preferred immediate rewards over delayed and

45 bigger rewards. A study that examined academic procrastination and goal achievement on a

46 weekly basis of web-based protocols (Wäschle, Allgaier, Lachner, Fink and Nückles, 2014)

47 found that high procrastinators were low on goal achievement, and in turn, low achievement

48 reinforced academic procrastination forming a positive feedback loop. Procrastination has been

49 described as a failure of self-control (Pychyl and Flett (2012) and as a meta-cognitive failure

50 (Fernie, Bharucha, Nikčević, and Spada, 2017).

51 Chu and Choi (2005) suggested a distinction between a non - adaptive type of

52 procrastination "passive", and an adaptive type of procrastination "active". While passive

53 procrastination is a self-destructive process in which self-doubt, anxiety, and distress accompany

54 the non-accomplishment of tasks, and the failure to meet deadlines, active procrastination is a

55 self-regulating time-management strategy that allows working under pressure and meeting

56 deadlines successfully. Choi and Moran (2009) proposed and validated an active procrastination

57 scale in a sample of undergraduate college students, which measured four components of active

58 procrastination: Preference for pressure, intentional decision to procrastinate, the ability to meet

59 deadlines, and outcome satisfaction. This active procrastination scale was validated against

60 academic performance. Students high in active procrastination had higher grades, and greater 
61 self-reported academic performance. In their study active procrastination, and in particular the

62 ability to meet deadlines, correlated positively with personality traits that confer resilience,

63 conscientiousness and emotional stability (Choi and Moran, 2009).

64 There has been extensive work tying procrastination types with emotional intelligence.

65 Emotional intelligence (EI) was defined by Salovey and Mayer (1990, page 189) as "the ability

66 to monitor one's own and others' feelings and emotions, to discriminate among them and to use

67 this information to guide one's thinking and actions." If passive procrastination is a failure to

68 guide one's thinking and actions, while active procrastination is a strategy based on one's

69 excellent understanding of one's own motivations and resources, then surely EI would contribute

70 to active and diminish passive procrastination. There is some proof of this hypothesis. EI has

71 been found to be negatively associated with procrastination by employees in the workplace

72 (Wan, Downey \& Stough, 2014) and in college students trying to meet college requirements

73 (Deniz, Tras, and Aydogan, 2009). It has also been found to mediate the relationship between

74 procrastination and academic achievement in students with and without learning disabilities (Hen

75 \& Goroshit 2014). As Peña-Sarrionandia, Mikolajczak, and Gross (2015) show in their meta-

76 analysis, emotional intelligence is closely linked with emotion regulation, and thus is a trait that

77 is tied to the behavior regulation necessary for avoiding procrastination. Moreover, there is some

78 evidence for a causal relationship between emotional intelligence and procrastination. Eckert,

79 Ebert, Lehr, Sieland, and Berking, (2016) showed in a randomized controlled trial, that an

80 intervention enhancing emotional intelligence had a significant effect on reducing

81 procrastination.

82 Kim, Fernandez and Terrier (2017) studied active and passive procrastination in college

83 students. They found that the two were negatively correlated. In terms of personality traits, 
84 passive procrastination was positively correlated with neuroticism, and negatively with

85 conscientiousness, while active procrastination showed the reverse pattern of correlations. When

86 personality traits and procrastination scores were used to predict GPA, passive procrastination

87 negatively contributed to GPA while active procrastination did so positively. Thus passive

88 procrastination is related to neuroticism, while active procrastination is related to resilient

89 personality as well as to greater academic success. Similar findings were reported by Zhou

90 (2018) for both male and female college students in a vocational college. Seo (2012) found that

91 when both active and passive procrastinators study for the same length of time before an exam,

92 active procrastinators get higher grades than do passive procrastinators. Active procrastination

93 was found to be positively related to creative ideation and creative self-efficacy (Liu, Pan, Luo,

94 Wang and Pang, 2017) and to internal motivation and students' well-being (Habelrih \& Hicks,

95 2015). Other studies that compared active and passive procrastination found that, while in both

96 cases a behavioral delay is apparent, the motivational variables underlying active procrastination

97 are completely different from those underlying passive procrastination. Corkin, Yu and Lindt,

98 (2011) suggested calling active procrastination active delay. On the other hand, Chowdhury and

99 Pychyl (2018) have argued that active procrastination may not be a wholly beneficial or a unitary

100 construct. Like others, they point out that being active and procrastinating are mutually

101 incompatible; purposeful delay is the adaptive component of what is commonly referred to as

102 active procrastination. The other component, arousal delay, is the need for high arousal which

103 can be experienced by certain individuals only by delaying the execution of tasks until the

104 deadline produces palpable external pressure. This arousal delay is maladaptive and is negatively

105 correlated with personality traits bestowing resilience, while purposeful delay is positively

106 correlated with the same traits. 

personality (Steel, 2007). While this model of personality has much to commend it, it is not helpful in distinguishing between earlier developing temperamental tendencies, and later

110 developing, character traits. The temperament and character model of personality (Cloninger, 111 2004) posits that personality is two-tiered: (1) Temperament is present early in development,

112 before language acquisition, and individual differences in temperament are related to individual 113 differences in brain structure and function. Thus temperament traits tend to be pre- or

114 unconscious, and stabilize relatively early in development. (2) The second tier of personality is 115 character, formed later in development, in transaction with the environment, and influenced by 116 the individual's temperament. Character traits are more accessible to the individual, and more 117 susceptible to change (Cloninger, 2004). Moreover, character traits are central to self-regulation 118 and self-management. Some support for the earlier development of temperament vs. character is 119 to be found in longitudinal studies (Zohar, Zwir, Wang, Cloninger, \& Anokhin, 2018). The temperament and character model of personality is consistent with personality traits not working independently of each other; rather, trait combinations interact to wield influence on the individual's cognitions, feelings and actions (Cloninger 2004, Cloninger \& Zwir, 2018) forming temperament and character profiles. According to the temperament and character model of personality (Cloninger, Przybeck, 125 Svrakić, \& Wetzel, 1994) there are four temperament traits: Novelty Seeking (NS), an excitatory tendency related to curiosity, exploration, and impulsivity; Harm Avoidance (HA), an inhibitory tendency related to risk aversion, pessimism and anxiety; Reward Dependence (RD) the extent to which an individual is affected by social cues, is sentimental, and shares his emotional experiences, and Persistence (PS), the temperamental drive that resists the extinction of learned 
130 associations and promotes ambition, perfectionism, and toleration of frustration. Individuals

131 who are high in RD and PS, and low in HA and NS, those with a dependable temperament

132 profile, tend to be better adjusted, and lead healthier, happier, and more productive lives

133 (Cloninger \& Zohar, 2011). Thus if active procrastination is a helpful time-management

134 strategy, misnamed as procrastination, it should be associated with a dependable temperament

135 profile, while passive procrastination, a self-destructive and distressing behavior should not.

136 There are three character traits: Self-Directedness (SD), the character trait that allows

137 individuals to accept themselves, to define personal goals and to mobilize personal resources to

138 work in a directed way in order to achieve these goals; Cooperation (CO), the ability to accept

139 others and to work with them in a principled and equitable way, and Self-Transcendence (ST),

140 the feeling that one is part of a bigger whole, and is open to spiritual experience. Being high in

$141 \mathrm{SD}$ and $\mathrm{CO}$ is an indication of a mature personality, just as being low in these two character

142 traits predisposes individuals to personality disorders (Cloninger \& Svrakić, 2016). Being high in

143 all three character traits, being of well-developed character, is related to happiness, health and

144 health behavior (Cloninger and Zohar, 2011) and to greater coherence of heart rate variability

145 (Zohar, Cloninger and McCraty, 2013). Individuals with a well-developed character profile are

146 more able to regulate their behavior, in conjunction with their temperament and environmental

147 demands in order to meet their personal goals, while working with others, in the service of a

148 greater good (Cloninger, 2004). Thus, if the well-developed character profile is associated with

149 active procrastination, it will provide further proof that active procrastination is not a failure of

150 self-management but rather a successful strategy; while we expect that passive procrastination

151 will not be associated with the well-developed character profile. 
153 of the bio-psycho-social personality model of temperament and character as well as in terms of 154 emotional intelligence. The study hypotheses were:

155

156

157

158

159

160

161

162

163

164

165

166

167

168

169

170

171

172

173

$174023 \mathrm{~L} / \mathrm{nd}$. The study was put on a Qualtrics (2003) platform, and the first screen provided

175 information on the study, gave contact details of the authors, and required written consent so as

(1) There will be a negative association between active and passive procrastination.

(2) Passive procrastination will be associated with less effective goal attainment, while active procrastination will be associated with more effective goal attainment.

(3) Active procrastinators will be higher on EI than Passive procrastinators.

(4) Active and Passive procrastinators will have different levels of personality traits: Active procrastinators will be lower in HA, higher in RD and PS, as well as in SD and $\mathrm{CO}$.

(5) Active Procrastinators will have score higher than the Passive Procrastinators on the dependable temperament profile score.

(6) Active Procrastinators will score higher on the well-developed character profile than the Passive Procrastinators.

\section{Materials \& Methods}

Participants

The participants were 126 healthy community volunteers of whom $22(17.4 \%)$ were men; their average age was $28.9 \pm 9$

Procedure

The study received the approval of the Ruppin Academic Center Ethics committee 2017- 
176 to continue to the next screen. Participants were either psychology majors who participated for

177 credit, or individuals who answered a Facebook or WhatsApp invitation with the link to the

178 study. Participants were rewarded for their participation by a raffle of a voucher for a breakfast

179 for two. The study design was short-term longitudinal. At base-line participants reported on the

180 TCI-140, as well as being asked to formulate three goals they wished to achieve within the next

181 two weeks, and to specify their action plan for each goal. Two weeks later, the participants were 182 sent a link in which they were asked to self-report on the TPS, APS, and the EI. At the end of 183 this Self-Report they were presented with the three goals they had formulated two weeks before, 184 and asked to report if they had achieved each of the goals, partially achieved it, or not at all.

185 Participants' privacy and anonymity were protected throughout.

186 Instruments

187 1. Tuckman Procrastination Scale (TPS; Tuckman, 1991): The TPS has 16 items that assess 188 procrastination, and are answered on a 7-point Likert-like response scale. Sample items 189 are "I needlessly delay finishing jobs, even when they're important" and "I am an incurable timewaster". The internal reliability of the TPS in this study was $\alpha=0.95$.

2. Active Procrastination Scale (APS; Choi \& Moran, 2009). The APS has 16 items that are answered on a 7-point Likert-like response scale. Sample items are "I finish most of my tasks exactly on deadline, because that is how I choose to operate" or "So as to make the maximal use of my time, I intentionally put off some of my tasks". In the current study the internal consistency of the APS was $\alpha=0.78$.

3. The Temperament and Character Inventory (TCI-140; Cloninger, Pryzbeck \& Svrakić, 1994): The TCI-140 includes 140 items which are answered on a 5-point Likert-like response scale. The scale includes 20 items for each of the seven traits it measures except 
for Self-Direction, which has only 16 items, allowing for a 4-item validity scale. The TCI measures four temperament traits: Novelty Seeking (NS) in the current study had internal consistency of $\alpha=0.64$; Harm Avoidance (HA) had internal consistency of $\alpha=0.88$; Reward Dependence (RD) had internal consistency of $\alpha=0.79$, and Persistence had internal consistency of $\alpha=0.84$. In addition, the TCI measures three character traits. SelfDirectedness (SD) had internal consistency of $\alpha=0.88$; Cooperation (CO) had internal consistency of $\alpha=0.78$; and Self-Transcendence (ST) had internal consistency of $\alpha=0.89$. A description of the traits, and of the psychometric properties of the TCI-140 is given in Zohar \& Cloninger (2011).

4. Emotional Intelligence (EI; Schutte et al., 1998). The EI includes 33 items which are answered on a 5-point Likert-like response scale. Sample items are "Other people find it easy to trust me" or "I control my emotions". In the current study the EI had internal consistency of $\alpha=0.89$.

5. Personal Goals. At first measurement, respondents were asked to list three personal goals which they wanted to achieve within the next two weeks. For each of their three stated goals they were asked if they had an action plan (score of 3) a partial plan (score of 2) or no plan at all (score of 1). Two weeks later they were asked to specify on a three-point scale the degree to which they had achieved each of their previously defined goals and could answer that the goal was achieved (score of 3) partially achieved (score of 2) or not achieved (score of 1). Each participant thus could score 3-9 on the degree of planning at Time 1 and the degree of actual procrastination at Time 2 with a potential range of 3-9. The mean score over the three action plans was the participant's Goal Planning (GP) 
221

222

223

224

225

226

227

228

229

230

231

232

233

234

235

236

237

238

239

240

241

242

243

244

245

score, while the mean level of goal achievement over the three goals was the participant's progress in personal goals (PPG).

\section{Data Analysis}

Data was downloaded from the Qualtrics platform into SPSS files. All analyses were conducted in SPSS 23. Descriptive statistics and correlations were conducted on the continuous variables. In addition, we made a median split of the Passive and Active procrastination scale scores, to produce a "high" and "low" score on each, which allowed for dividing the sample into four groups. A crosstabs procedure with the Chi-square statistic was used to test for an association between high and low active and passive procrastination. An analysis of variance was conducted comparing these 4 groups for personality traits and EI. Then a dependable temperament profile was formed by adding RD and PS and subtracting HA and NS, thus giving a single temperament score for each participant; and a welldeveloped character profile was formed using the product of the three character trait scores (Zohar, Zwir, Wang, Cloninger, and Anokhin, 2018).

\section{Results}

\section{Descriptive Statistics}

Table 1 shows the means, standard deviations and inter-correlations of the study variables. The correlations are all in the expected directions, and most of them (those appearing in bold font) are significant at $\mathrm{p}<0.01$. The inter-correlations between the seven traits of the TCI are weak or moderate, as are the other significant correlations in the Table. 
Table 1 about here

248

Content analysis of the personal goals listed by the participants to be achieved within the next two weeks were highly varied in domain and specificity. The most frequent domain was academic tasks and academic success (30.8\%). Examples of academic goals were: "finish all the reading assignments"; "hand in the psychology homework"; "get down to studying". Work related goals constituted $12.7 \%$ of the entries. Examples were "Get a raise", "complete 20 placements", and "feel confident in myself, in the next challenge of my dream job". Many participants related to physical activity $(11.4 \%)$. Some quite specifically "run 12 km." "swim 3 times" but also more generally "exercise" or "start physical activity". The next most frequent domain was body weight (8.7\%) "lose weight" or more specifically "lose 2 kilograms". Health behaviors were the next most frequent category (6.7\%) and included goals like "smoke less marijuana" "go to the doctor", and "eat a healthy balanced diet and cut down on sweets". Domestic goals constituted $6 \%$ and included goals like "go over the children's rooms" but also "buy house". Another 5\% described goals having to do with leisure, such as "rest", or "go abroad". These seven categories together describe $81.9 \%$ of the personal goals. In addition, there were some interpersonal goals like "spend uninterrupted quality time with my daughter" or "reconciliation with my friend R.". Of the remainder some were too general to classify e.g. "success". Some were highly specific and personal: "when I next visit home remain warm and friendly toward my family even though therapy has revealed some troubling issues" or "attend Rainbow gathering". 
Hypothesis 1: There will be a negative association between active and passive procrastination

271

272

273

274

275

276

277

278

279

280

281

282

283

284

285

286

287

288

289

290

291
As can be seen in Table 1 there was a negative correlation between the two $(\mathrm{r}=-.311$, $\mathrm{p}<0.01$ ), supporting the negative association hypothesized.

Median splits were made for the TPS and the APS producing high and low passive procrastinators and high and low active procrastinators respectively. Table 2 shows their distribution. Numerically the high-high and low-low group were bigger than the high-low groups along the other diagonal. However, this difference was not statistically significant according to the Chi-square test $(\chi 2=0.29, \mathrm{p}>0.05)$. Fully $19.8 \%$ of the participants were high on both forms of procrastination, and $23 \%$ were low on both. Thus when dichotomized, there is no negative association between high and low active and passive procrastination. This does not support hypothesis 1 ,

Table 2 about here

Hypothesis 2: Passive procrastination will be associated with less effective goal attainment, while active procrastination will be associated with more effective goal attainment.

The passive procrastination score was moderately and negatively correlated with having formed action plans for personal goals and for progress in personal goals, thus the higher an individual in passive procrastination the less well-formed were his action plans for achieving his personal goals, as well as being less effective in attaining his personal goals. Active procrastination was weakly and positively correlated with formulating action plans and with goal achievement suggesting an 
292

293

294

295

296

297

301

302

303

304

305

306

307

308

309

advantage for active procrastinators in forming action plans and with achieving their personal goals. These correlations lend support to hypothesis 2 .

Hypotheses 3\&4: Active procrastinators will be higher on EI than Passive procrastinators.

Active and Passive procrastinators will have different levels of personality traits:

Active procrastinators will be lower in HA, higher on RD and PS, as well as higher on SD and CO.

To test these hypotheses we conducted analysis of variance With Bonferroni correction for multiple post-hoc comparisons. To be conservative we included all 4 groups -Active Procrastinators, Passive Procrastinators, Both and NonProcrastinators.

As is shown in Table 3, hypotheses 3 and 4 were largely supported. Active procrastinators were significantly higher than passive procrastinators on the following traits: Emotional Intelligence, Persistence, Self-Directedness and Cooperation, and significantly lower on Novelty Seeking and Harm Avoidance. Contrary to hypothesis 4 , Reward Dependence was no different between the 4 procrastination groups.

310

311 Hypothesis 5: Active Procrastinators will score higher than Passive Procrastinators on the 312 dependable temperament profile (RD+PS-HA-NS). 
313

314

315
Oneway analysis of variance was conducted for dependable temperament (high Reward Dependence, high Persistence, low Harm Avoidance and low Novelty Seeking) for the four procrastinations groups. The four groups were very different for dependable temperament $\mathrm{F}(3,122)=19.37, \mathrm{p}<0.0001$. Post-hoc comparisons with Bonferroni correction for multiple comparisons showed that passive procrastinators were significantly lower than the other three groups, and active procrastinators were higher than the passive procrastinators and the passive-active procrastinators "both". The means of the four groups + the SE is shown in Figure 1.

Figure 1 about here

Hypothesis 6: Active Procrastinators will score higher than Passive Procrastinators on the well-developed character profile (SD X COX XT).

Oneway analysis of variance was conducted for well-developed character (high Self-Directedness, high Cooperation, and high Self-Transcendence) for the four procrastination groups. The four groups were significantly different $F(3,122)=5.79, p<0.001$. Post-hoc comparisons with Bonferroni correction for multiple comparisons showed that active procrastinators were higher than the passive procrastinators and the non-procrastinators "none". The means of the four groups + the SE is shown in Figure 2. 


\section{Discussion}

337

338

In the current study the scale scores of passive and active procrastination correlated

negatively, as expected, showing that these are contradictory behavioral tendencies. This is

340

consistent with the findings of Kim, Fernandez and Terrier (2017) and others. Passive

341

procrastination scores correlated negatively with action plans for personal goals at baseline and

342

on goal achievement two weeks later, while active procrastination had positive correlations. The

343

avoidance that is passive procrastination is non-functional while the strategy of active

344 procrastination is useful in discharging one's goals. This shows the efficacy of active

345 procrastination as has been reported by others (e.g. Habelrih \& Hicks, 2015).

In the current study we compared four groups formed by dividing the respondents above

347 and below the median for the active and passive procrastination scale scores. This procedure

348 resulted in four groups: those high in passive procrastination and low in active procrastination

349 "passive procrastinators"; Those high in active procrastination and low in passive procrastination

350 "active procrastinators"; Those above the median for both forms of procrastination "active-

351 passive procrastinators"; and those below the median for both "non-procrastinators". The

352 median split of the scales produced four nearly equal groups in number. It is not quite clear how

353 being high on both forms of procrastination might manifest itself. It is possible that these

354 different tendencies are expressed in different ways at different times. Active procrastination has

355 four components (Choi and Moran, 2009): (1) A preference for pressure that motivates

356 individuals to delay until the perceived pressure exerted by the encroaching deadline rises above

357 threshold. (2) An intentional decision to delay in discharging a task (3) An ability to meet

358 deadlines and (4) Satisfaction with the outcome. Unlike passive procrastination, active

359 procrastination is not a unitary concept (Chowdhury and Pychyl, 2018), and it is possible that 
360 those high in active procrastination are not equally high in all its components. For consistency,

361 we conducted the analyses and comparisons between all four groups.

362 When each trait was considered separately, active procrastinators were significantly higher

363 than passive procrastinators on: Emotional Intelligence, Persistence, Self-Directedness, and

364 Cooperation. Thus the active procrastinators were more aware of their emotions and those of

365 others and were better able to manage themselves and avoid distress (high EI), they were more

366 ambitious, perfectionistic and frustration-tolerant (high PS), they were more goal-oriented,

367 responsible, resourceful, and more self-accepting (high SD), as well as more empathic, more

368 helpful, and more accepting of others (high $\mathrm{CO}$ ). Active procrastinators were significantly lower

369 than passive procrastinators on Harm Avoidance and Novelty Seeking, i.e. they were less

370 pessimistic, less fatigable, less shy, and less wary of the unexpected (low HA), as well as less

371 impulsive, more rule-bound, and less explorative (low NS). Thus the two groups were different

372 in the expected directions for six of the eight psychological traits measured in this study. These

373 results are consistent with previous research that found that effective time-management was

374 positively associated with emotional intelligence (Cerezo, Esteban, Sánchez-Santillán, and

375 Núñez, 2017). Emotional intelligence includes the ability to monitor one's own and others

376 feelings and emotions, to discriminate among them and to use them to guide one's actions

377 (Salovey and Mayer 1990). Thus active procrastinators can keep their motivation and energy

378 harnessed by time-regulation strategies that suit their circumstances as well as their temperament

379 and character. The temperament and character differences between the Active and Passive

380 Procrastinators all favor Active over Passive Procrastinators in that they are associated with

381 greater physical and mental health (Cloninger and Zohar, 2011; Zohar Cloninger \& McCraty, 
382 2013), happiness (Cloninger, 2004), and greater productivity (Kono, Uji, and Matsushima, 383 2015).

384 In addition to comparing the groups for individual traits, we were able to use the 385 temperament and character model of personality (Cloninger, 2004) in order to form two 386 personality profiles: (1) the dependable temperament profile, i.e. high in Reward Dependence 387 and Persistence and low in Harm Avoidance and Novelty Seeking. Individuals possessing this 388 combination of temperament trait scores tend to be emotionally and behaviorally well-regulated, sociable (high RD) as well as hard-working and tolerant of frustration (high PS). They neither avoid challenges nor worry over much about the consequence of tackling them (low HA) nor do they tend to act impulsively (low NS). The temperament traits act together in individuals to bring about this harmonious and stable profile (Zohar, Zwir, Wang, Cloninger, and Anokhin, 2018). (2) Well-developed character: individuals high in all three character traits, self-directedness,

394 cooperation, and self-transcendence, are able to weather the demands their temperament and 395 their environment make on them, engaging in self-directed goal-oriented behavior (high SD) working well with others in a respectful way while being empathic and helpful to others (high $397 \mathrm{CO}$ ) in order to achieve meaningful goals (high ST). The combination of being high in all three lends the individual resilience and happiness (Cloninger and Zohar 2011). We compared the four groups of procrastinators by means of analysis of variance on these two personality profile. For both, passive procrastinators were significantly lower than all three other groups and in particular lower than active procrastinators. Thus active procrastinators are more dependable and have better developed character than passive procrastinators. 
405 tendency) have shared genetic variance. In a further study, Gustavson et al. (2017) showed that 406 procrastination was genetically related to the executive function of planning and to internalizing 407 and externalizing psychopathology.

408 Even though temperament and procrastination are genetically influenced they are also 409 subject to environmental influence. Glick and Orsillo (2015) tested the efficacy of acceptance410 based behavioral therapy for academic procrastination targeting time management. The stated 411 goal of the interventions was to reduce procrastination regarding assigned reading in an 412 undergraduate and a graduate class. Glick and Orsillo (2015) failed to bring about an 413 improvement in the participants as a whole, although they did find a significant interaction 414 students high in academic values improved their procrastination in response to time-management 415 intervention while those low in academic values were not affected. However, De Paola and 416 Scoppa (2015), showed that a simple intervention of setting deadlines improved undergraduates' 417 performance if they were heavy procrastinators. Hen and Goroshit (2018) in their editorial, 418 conclude that cost- and time-efficient interventions for procrastination can be deployed in 419 academic settings, and are especially important for learning disordered students.

420 This study should be read with its limitations in mind. This was a self-selected sample of 421 community volunteers, and included no known extremes of procrastination. All measures were

422 self-reported, including the personal goals, the action plans for goal implementation, and the 423 report of goal attainment. We allowed only two weeks latency between the two measurements, 424 making the window for prediction very short. It is possible that with deadlines that are months or 425 even years in the future, such as those set in graduate school, procrastination of all kinds is not 426 helpful. A bigger random sample, longer latency between T1 and T2, and some objective 
427 measures that are not self-reported would constitute improvements. Without extension and 428 replication, it is not clear how generalizable the results and conclusions of this study are. 429 In conclusion, this study offers additional support for the adaptive aspects of active 430 procrastination. Active procrastination contributed to goal attainment within a two-week 431 deadline, while passive procrastination did not. Participants high in active procrastination were 432 associated with the dependable temperament, and well-developed character and higher emotional 433 intelligence. The results of the current study give further support that what is now often called 434 active procrastination might better be viewed as planned, purposeful time- and self-management 435 strategy. 


\section{References}

438 Ariely, D., \& Wertenbroch, K. (2002). Procrastination, deadlines, and performance: Self-control 439 by precommitment. Psychological Science, 13(3), 219-224.

440 Cerezo, R., Esteban, M., Sánchez-Santillán, M., \& Núñez, J. C. (2017). Procrastinating behavior 441 in computer-based learning environments to predict performance: A case study in 442 Moodle. Frontiers in Psychology, 8, 1403.

443 Chu, A. H. C., Choi, J. N. (2005). Rethinking procrastination: Positive effects of "active" 444 procrastination behavior on attitudes and performance. The Journal of Social Psychology, $145,245-264$.

446

447

448

449

450

451

452

453

454

455

456

457 458

Choi, J. N., \& Moran, S. V. (2009). Why not procrastinate? Development and validation of a new active procrastination scale. The Journal of Social Psychology, 149(2), 195-212.

Chowdhury, S. F., \& Pychyl, T. A. (2018). A critique of the construct validity of active procrastination. Personality and Individual Differences, 120, 7-12.

Cloninger, C. R., Przybeck, T. R., Svrakić, D. M., \& Wetzel, R. D. (1994). The Temperament and Character Inventory: A guide to its development and use. St. Louis: Washington University Center for Psychobiology of Personality.

Cloninger, C. R. (2004). Feeling good: the science of well-being. Oxford: Oxford University Press.

Cloninger, C. R., \& Zohar, A. H. (2011). Personality and the perception of health and happiness. Journal of Affective Disorders, 128(1-2), 24-32.

Cloninger, C. R., \& Svrakić, D. M. (2016). Personality disorders. In The medical basis of psychiatry (pp. 537-550). Springer, New York, NY. 
459 Cloninger, C. R., \& Zwir, I. (2018). What is the natural measurement unit of temperament: single 460 traits or profiles? Philosophical Transactions of the Royal Society, B, 373(1744), 20170163.

462 Corkin, D. M., Shirley, L. Y., \& Lindt, S. F. (2011). Comparing active delay and procrastination 463 from a self-regulated learning perspective. Learning and Individual Differences, 21(5), $464 \quad 602-606$.

465 Deniz, M., Tras, Z., \& Aydogan, D. (2009). An investigation of academic procrastination, locus 466 of control, and emotional intelligence. Educational Sciences: Theory and Practice, 9(2), $467 \quad 623-632$.

468 De Paola, M., \& Scoppa, V. (2015). Procrastination, academic success and the effectiveness of a 469 remedial program. Journal of Economic Behavior \& Organization, 115, 217-236.

470 Eckert, M., Ebert, D. D., Lehr, D., Sieland, B., \& Berking, M. (2016). Overcome procrastination: Enhancing 471 472

473 Fernie, B. A., Bharucha, Z., Nikčević, A. V., \& Spada, M. M. (2017). A meta-cognitive model of 474 procrastination. Journal of Affective Disorders, 210, 196-203.

475 Glick, D. M., \& Orsillo, S. M. (2015). An investigation of the efficacy of acceptance-based 476 behavioral therapy for academic procrastination. Journal of Experimental Psychology: 477 General, 144(2), 400-409.

478 Gustavson, D. E., Miyake, A., Hewitt, J. K., \& Friedman, N. P. (2015). Understanding the 479 cognitive and genetic underpinnings of procrastination: Evidence for shared genetic 480 influences with goal management and executive function abilities. Journal of Experimental $481 \quad$ Psychology: 144(6), 1063. 
482 Gustavson, D. E., du Pont, A., Hatoum, A. S., Rhee, S. H., Kremen, W. S., Hewitt, J. K., \& 483 Friedman, N. P. (2017). Genetic and environmental associations between procrastination 484 and internalizing/externalizing psychopathology. Clinical Psychological Science, 5(5), $485 \quad 798-815$.

486 Habelrih, E. A., \& Hicks, R. E. (2015). Psychological well-being and its relationships with active 487 and passive procrastination. International Journal of Psychological Studies, 7(3), 25-34.

488 Hen, M., \& Goroshit, M. (2014). Academic procrastination, emotional intelligence, academic 489 self-efficacy, and GPA: A comparison between students with and without learning disabilities. Journal of Learning Disabilities, 47(2), 116-124.

491

492

493

494

495

496

497

498

499

500

501

502

503

Hen, M., \& Goroshit, M. (2018). Prevention and intervention for academic procrastination in academic communities. Journal of Prevention \& Intervention in the Community, 46(2), 113-116.Kim, S., Fernandez, S., \& Terrier, L. (2017). Procrastination, personality traits, and academic performance: When active and passive procrastination tell a different story. Personality and Individual Differences, 108, 154-157.

Liu, W., Pan, Y., Luo, X., Wang, L., \& Pang, W. (2017). Active procrastination and creative ideation: The mediating role of creative self-efficacy. Personality and Individual Differences, 119, 227-229.

Peña-Sarrionandia, A., Mikolajczak, M., \& Gross, J. J. (2015). Integrating emotion regulation and emotional intelligence traditions: a meta-analysis. Frontiers in Psychology, 6, 160.

Pychyl, T. A., \& Flett, G. L. (2012). Procrastination and self-regulatory failure: An introduction to the special issue. Journal of Rational-Emotive \&Cognitive Behavioral Therapy, 30(4), 203-212. 
504 Richardson, M., Abraham, C., \& Bond, R. (2012). Psychological correlates of university

505 students' academic performance: A systematic review and meta-analysis. Psychological 506 Bulletin, 138(2), 353-387. doi: 10.1037/a0026838.

507 Salovey, P., \& Mayer, J. D. (1990). Emotional intelligence. Imagination, Cognition and 508 Personality, 9(3), 185-211.

509 Schutte, N. S., Malouff, J. M., Hall, L. E., Haggerty, D. J., Cooper, J. T., Golden, C. J. \& 510 Dornheim, L. (1998). Development and validation of a measure of emotional intelligence.

$511 \quad$ Personality and Individual Differences, 25(2), 167-177.

512 Seo, E. H. (2012). Cramming, active procrastination, and academic achievement. Social 513 Behavior and Personality, 40(8), 1333-1340.

514 Sirois, F. M., \& Kitner, R. (2015). Less adaptive or more maladaptive? A meta-analytic 515 investigation of procrastination and coping. European Journal of Personality, 29(4), 433$516 \quad 444$.

517 Steel, P. (2007). The nature of procrastination: A meta-analytic and theoretical review of self518 quintessential regulatory failure. Psychological Bulletin, 133, 65-94.

519 Tuckman, B. W. (1991). The development and concurrent validity of the procrastination scale. 520 Educational and Psychological Measurement, 51(2), 473-480.

521 Wan, H. C., Downey, L. A., \& Stough, C. (2014). Understanding non-work presenteeism:

522 Relationships between emotional intelligence, boredom, procrastination and job 523 stress. Personality and Individual Differences, 65, 86-90.

524 Wäschle, K., Allgaier, A., Lachner, A., Fink, S., \& Nückles, M. (2014). Procrastination and self525 efficacy: Tracing vicious and virtuous circles in self-regulated learning. Learning and 526 Instruction, 29, 103-114. 
527 Wu, H., Gui, D., Lin, W., Gu, R., Zhu, X., \& Liu, X. (2016). The procrastinators want it now:

528 behavioral and event-related potential evidence of the procrastination of intertemporal $529 \quad$ choices. Brain and Cognition, 107, 16-23.

530 Kono, Y., Uji, M., \& Matsushima, E. (2015). Presenteeism among Japanese IT employees:

531 personality, temperament and character, job strain and workplace support, and mental $532 \quad$ disturbance. Psychology, 6(15), 1971.

533 Zohar, A. H. \& Cloninger C. R. (2011). The psychometric properties of the TCI-140 in Hebrew. 534 European Journal of Psychological Assessment, 27(2), 73-80.

535 Zohar, A.H., Zwir, I., Wang, J., Cloninger, C.R., \& Anokhin, A. (2018). The development of 536 temperament and character during adolescence: Gender differences in two phases of change.

537 Developmental Psychopathology, 1-17.

538 Zhou, M. (2018). Gender differences in procrastination: The role of personality traits. Current 539 Psychology, 1-9. 
Figure $\mathbf{1}$ (on next page)

Dependable temperament scores for the four procrastination groups 


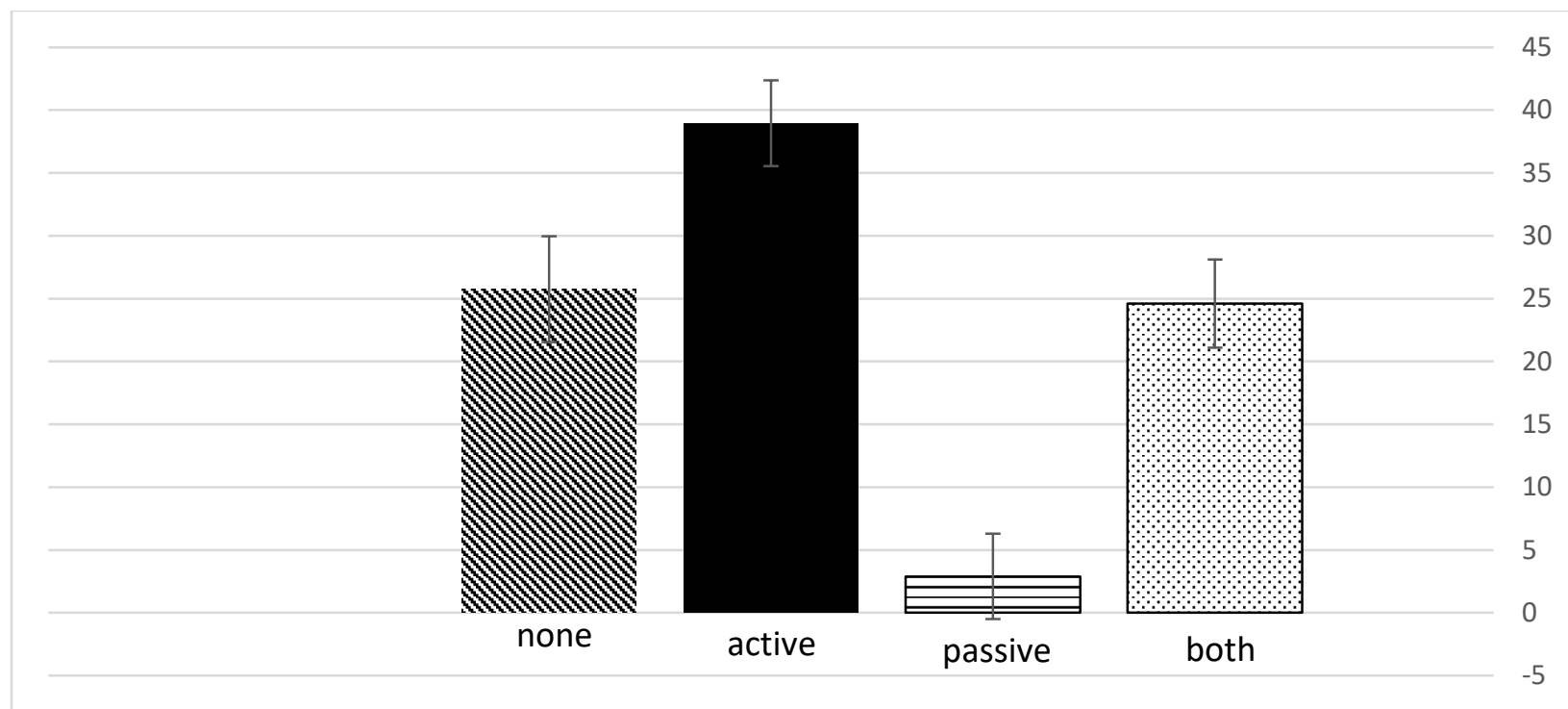




\section{Table $\mathbf{1}$ (on next page)}

Descriptives and Correlations for Study Variables $(\mathrm{N}=126)$ 
Table 1. Descriptives and Correlations for Study Variables $(\mathrm{N}=126)$

\begin{tabular}{|c|c|c|c|c|c|c|c|c|c|c|c|}
\hline & HA & $\mathrm{RD}$ & PS & SD & $\mathrm{CO}$ & $\mathrm{ST}$ & AP & $\mathrm{PP}$ & EI & GP & PPG \\
\hline NS & -.242 & .127 & -.093 & -.334 & -.148 & .444 & -.019 & .370 & .128 & -.138 & -.265 \\
\hline HA & -- & -.236 & -.406 & -.494 & -.247 & -.136 & -.512 & .305 & -.490 & -.329 & -.270 \\
\hline $\mathrm{RD}$ & -- & -- & .252 & .257 & .467 & .131 & .185 & -.183 & .336 & .118 & .121 \\
\hline PS & -- & -- & -- & .399 & .278 & .000 & .388 & -.533 & .377 & .345 & .196 \\
\hline SD & -- & -- & -- & -- & .544 & -.083 & -.384 & -.631 & .355 & .469 & .406 \\
\hline $\mathrm{CO}$ & -- & -- & -- & -- & -- & .115 & .235 & -.280 & .373 & .124 & .145 \\
\hline ST & -- & -- & -- & -- & -- & -- & .007 & .075 & .113 & -.044 & -.080 \\
\hline AP & -- & -- & -- & -- & -- & -- & -- & -.311 & .315 & .244 & .266 \\
\hline PP & -- & -- & -- & -- & -- & -- & -- & -- & -.412 & -.444 & -.394 \\
\hline EI & -- & -- & -- & -- & -- & -- & -- & -- & -- & .258 & .329 \\
\hline GP & -- & -- & -- & -- & -- & -- & -- & -- & -- & -- & .347 \\
\hline Mean & 58.0 & 71.5 & 66.1 & 69.6 & 78.7 & 42.9 & 4.2 & 3.58 & 3.6 & 5.2 & 5.2 \\
\hline (SD) & (11.8) & $(9.1)$ & (10.9) & (11.4) & $(8.6)$ & $(12.6)$ & $(0.8)$ & (1.4) & (0.3) & $(1.4)$ & (1.4) \\
\hline
\end{tabular}

2 NS=Novelty Seeking; HA=Harm Avoidance; RD=Reward Dependence; PS=Persistence;

$3 \mathrm{SD}=$ Self-Directedness; $\mathrm{CO}=$ Cooperation; $\mathrm{ST}=$ Self-Transcendence; $\mathrm{AP}=$ Active Procrastination;

$4 \mathrm{PP}=$ Passive Procrastination; $\mathrm{EI}=$ Emotional Intelligence; $\mathrm{GP}=\mathrm{Goal}$ Planning - Action plans for

5 personal goals; $\mathrm{PPG}=$ progress on personal goals. 
Figure 2 (on next page)

Well-developed character scores for the four procrastination groups 


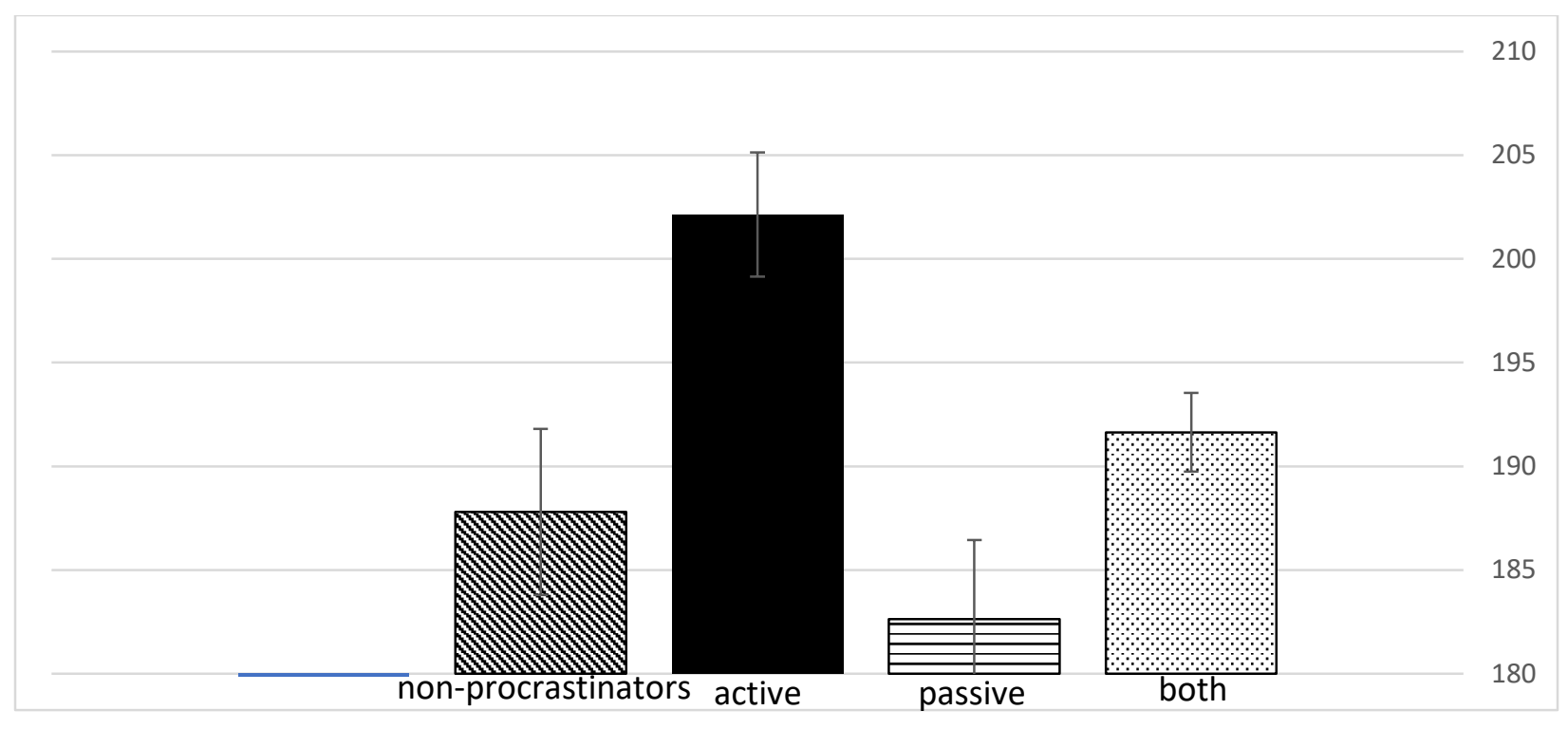


Table 2 (on next page)

Distribution of passive and active procrastinators 
Table 2. Distribution of passive and active procrastinators.

\section{Passive Procrastination}

\begin{tabular}{lcccc} 
& \multicolumn{2}{l}{ Low } & High & \\
\hline Active & Low & $29(23 \%)$ & $36(28.6 \%)$ & 65 \\
Procrastination & High & $36(28.6 \%)$ & $25(19.8 \%)$ & 61 \\
\hline & & 65 & 61 & 126
\end{tabular}

2 Although the High-Low groups are numerically smaller than the High-High and Low-Low

3 groups this difference is not significant, $\left(\chi^{2}=0.29, \mathrm{p}>0.05\right)$, i.e. there is no association between

4 the active and passive procrastination when dichotomized into high and low. 


\section{Table 3(on next page)}

Analysis of variance of the four procrastination groups for all individual traits measured 
1 Table 3 - Analysis of variance of the four procrastination groups for all individual traits measured

\begin{tabular}{|c|c|c|c|}
\hline Trait & Procrastination Group & Mean (SD) & $F(3,122)(p)$ \\
\hline EmotionaI & $\begin{array}{l}\text { Active Procrastinators } \\
\text { Passive Procrastinators }\end{array}$ & $\begin{array}{l}3.8(0.3)^{\mathrm{a}} \\
3.4(0.3)\end{array}$ & $8.6(0.001)$ \\
\hline Intelligence & $\begin{array}{l}\text { Both } \\
\text { Non-Procrastinators }\end{array}$ & $\begin{array}{l}3.7(0.2) \\
3.6(0.4)\end{array}$ & \\
\hline Novelty & $\begin{array}{l}\text { Active Procrastinators } \\
\text { Passive Procrastinators }\end{array}$ & $\begin{array}{l}53.6(7.5)^{\mathrm{a}} \\
58.3(9.4)\end{array}$ & $5.0(0.003)$ \\
\hline Seeking & $\begin{array}{l}\text { Both } \\
\text { Non-Procrastinators }\end{array}$ & $\begin{array}{l}61.3(8.2) \\
54.6(8.8)\end{array}$ & \\
\hline Harm & $\begin{array}{l}\text { Active Procrastinators } \\
\text { Passive Procrastinators }\end{array}$ & $\begin{array}{l}51.1(9.3)^{\mathrm{a}} \\
64.4(11.5)\end{array}$ & $11.7(0.001)$ \\
\hline Avoidance & $\begin{array}{l}\text { Both } \\
\text { Non-Procrastinators }\end{array}$ & $\begin{array}{l}54.4(7.8) \\
61.8(12.6)\end{array}$ & \\
\hline Reward & $\begin{array}{l}\text { Active Procrastinators } \\
\text { Passive Procrastinators }\end{array}$ & $\begin{array}{l}72.1(8.5) \\
63.4(10.4)\end{array}$ & $2.1(0.1)$ \\
\hline Dependence & $\begin{array}{l}\text { Both } \\
\text { Non-Procrastinators }\end{array}$ & $\begin{array}{l}72.9(8.2) \\
73.2(8.2)\end{array}$ & \\
\hline Persistence & $\begin{array}{l}\text { Active Procrastinators } \\
\text { Passive Procrastinators } \\
\text { Both } \\
\text { Non-Procrastinators }\end{array}$ & $\begin{array}{l}71.6(7.6)^{\mathrm{a}} \\
57.3(9.9) \\
67.4(10.7) \\
68.9(9.2)\end{array}$ & $15.8(0.001)$ \\
\hline Self & $\begin{array}{l}\text { Active Procrastinators } \\
\text { Passive Procrastinators }\end{array}$ & $\begin{array}{l}78.2(9.8)^{\mathrm{a}} \\
62.8(11.8)\end{array}$ & $14.9(0.001)$ \\
\hline Directedness & $\begin{array}{l}\text { Both } \\
\text { Non-Procrastinators }\end{array}$ & $\begin{array}{l}68.0(6.4) \\
68.8(9.7)\end{array}$ & \\
\hline Cooperation & $\begin{array}{l}\text { Active Procrastinators } \\
\text { Passive Procrastinators } \\
\text { Both } \\
\text { Non-Procrastinators }\end{array}$ & $\begin{array}{l}82.0(7.1)^{\mathrm{a}} \\
76.6(9.0) \\
78.9(7.7) \\
76.8(9.3)\end{array}$ & $3.2(0.02)$ \\
\hline Self & $\begin{array}{l}\text { Active Procrastinators } \\
\text { Passive Procrastinators }\end{array}$ & $\begin{array}{l}41.9(12.8) \\
43.3(12.0)\end{array}$ & $0.3(0.8)$ \\
\hline Transcendence & $\begin{array}{l}\text { Both } \\
\text { Non-Procrastinators }\end{array}$ & $\begin{array}{l}44.7(31.1) \\
42.1(12.8)\end{array}$ & \\
\hline
\end{tabular}

$2 \mathrm{a}=$ Active procrastinators significantly different from passive procrastinators in post-hoc comparisons with Bonferroni correction 
